\title{
IDÉIAS
}

\section{Parlamentarismo não}

\section{Resolve Nossa Crise}

José Richa

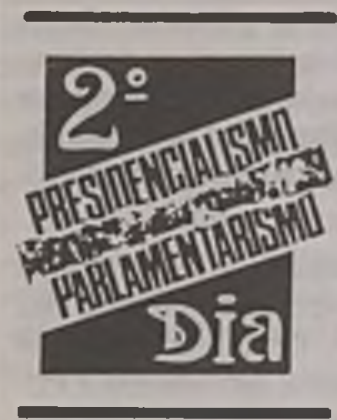

"Naturalmente, dentre os debatedores, o Senador Jarbas Passarinho, erudito, leva uma vantagem muito grande. Eu não tenho a sua erudição, mas aceitei vir aqui debater porque considero, ao longo desses anos, ter acumulado alguma experiência prática. Teoricamente não entendo quase nada do assunto, mas tenho uma vivência praticamente muito grande, que me permite fazer uma análise política da questão que se coloca neste seminário para o debate. E confesso que eu tenho uma grande simpatia pelo sistema parlamentarista de governo. Eu acho que o parlamentarismo permite que o poder seja compartilhado e, portanto, não exercido de forma absoluta por ninguém. Eu admito que, quando há crises no sistema parlamentarista de governo, estas crises afetam menos as instituições, pois elas se circunscrevem à área política. As crises no parlamentarismo são resolvidas muito mais rapidamente. E ai eu até discordo da opinião do Embaixador Nascimento Silva, quando toma o modelo francês como exemplo para dizer que as crises no parlamentarismo podem ocasionar o vazio no poder. Eu acho que pelo contrário. Nós aqui, no nosso sistema presidencialista, e em alguns outros paises presidencialistas, é que verificamos que quando há uma crise acaba ocorrendo uma crise no poder e aí, sim, acaba afetando as instituições, e acaba até ocasionando golpes de estado ou rupturas da legalidade democrática e dos postulados constitucionais.

E no parlamentarismo, quando se

José Richa é Senador pelo PMDB do Paraná, Debatedor no 2: Dia.

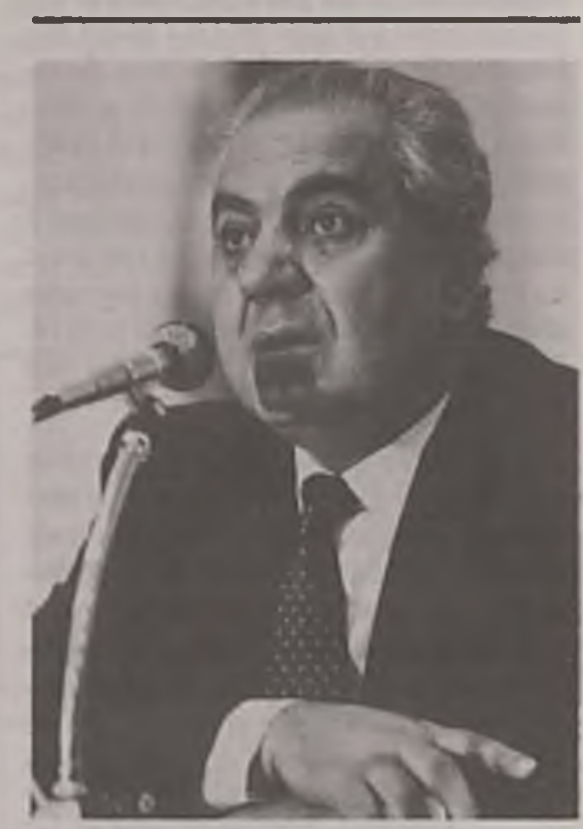

chega a um impasse diferente do presidencialismo, o impasse é solucionado. Ou cai o governo, o gabinete, ou é dissolvido o parlamento. Então há oportunidade de se solucionar politicamente as crises surgidas.

Entretanto, embora simpatizante, por todas as razões que eu já mencionei, pelo sistema parlamentarista, eu acho que não seria prudente de nossa parte adotá-lo agora, porque, no meu entendimento, há necessidade de alguns pré-requisitos, é preciso que criemos primeiro as condições para depois bem funcionar o parlamentarismo.

Eu tenho ouvido agora no debate, durante os trabalhos constituintes, muitos adeptos do parlamentarismo se contraditarem dizendo que nós jamais alcançaremos as pré-condições sem experimentar, sem adotar o sistema. Eu discordo por uma razão, que em parte coincide com os pontos de vista do Senador Jarbas Passarinho. É que nós não podemos nos utilizar do parlamentarismo para solucionar uma crise e, evidentemente, a crise conjuntural que nós atravessamos, que inclusive, e principalmente, politicamente é uma decorrência das mais de duas décadas de regime autoritário de governo que nós tivemos. Nós estamos, na verdade, pagando um certo preço por isso. Então, ninguém, nenhuma Nação do mundo sai de um regime autoritário de governo sem pagar algum preço. E nós podemos, até por convicção, chegarmos à conclusão de que neste instante o melhor sistema de governo é o parlamentarista e, entretanto, não termos condições efetivas de implantá-lo agora.

No meu entendimento estes prérequisitos, eu vou apenas mencionar, todo mundo já mencionou, mas apenas para conseguir desenvolver e concluir o meu raciocínio, no meu entendimento muitos são esses pré-requisitos para o bom desempenho do sistema parlamentar de governo. Dentre os requisitos, os principais eu alinharia. $O$ primeiro, um Congresso forte, com plenas prerrogativas e de boa qualidade.

Eu, como político, faço essa autocrítica. Infelizmente nós não somos políticos de boa qualidade. Nós temos que aprimorar a qualidade da nossa representação política. Eu costumo dizer sempre que, para que tenhamos um Congresso com plenas prerrogativas, um Congresso forte, não basta colocar na lei, por mais bem elaborados que sejam os seus dispositivos, não são suficientes para, de repente, transformar o Congresso, que durante o período autoritário não teve nenhuma das suas prerrogativas a não ser a prerrogativa cartorial, isto é, a de simplesmente chancelar as decisões tomadas, inclusive legislativas, pelo poder Executivo. Então, fora isso, o Congresso na verdade teve cassadas todas as suas prerrogativas. Mas não é pura e simplesmente redigindo, no capítulo do poder Legislativo, dispositivos muito bem elaborados que nós de repente vamos ter um Con- 
gresso forte, com plenas prerrogativas. Eu acho que o problema de prerrogativas na questão política decorre muito mais da qualidade das pessoas que vão compor do que propriamente do que está escrito na lei.

Outra questão, outro pré-requisito importantissimo é o de partido forte, partidos muito bem organizados. E nós, como vamos poder de repente ter estes partidos que nos faltam hoje, com profundas raízes populares, com pelo menos programas muito bem concatenados? Eu até nem acho que seja um prérequisito importante um partido ser forte e bem organizado, ter uma marca ideológica muito bem definida. Não acho isso essencial, mas um partido com um programa bem definido é extremamente importante. $\mathrm{E}$ isso também não é coisa que de repente a gente consiga. É preciso haver algum tempo de preparação. Eu até costumo dizer, quando vou debater com entidades de classe, principalmente com entidades de trabalhadores, a questão da organizacão partidária. É que, mesmo que estejamos convencidos de que, para ter uma democracia forte, e esta é a nossa convicção, precisamos ter partidos fortes. Mesmo que quiséssemos isso, nós não temos condições para exercitar. Imaginemos qualquer cidadão comum que tenha esta consciência: eu preciso entrar num partido político porque o partido político é o pulmão da democracia, é a base da organização da sociedade e por isso eu tenho um dever patriótico de ingressar num partido político. Quais as opções que ele tem? Quais as opçōes? Na verdade, por este quadro partidário atual, nós temos o partido do Dr. Ulysses, o partido do Dr. Brizola, o partido do Lula e assim por diante. Quer dizer, nós estamos, na verdade, sem condições, por falta de estruturar melhor a questão, nós não estamos dando à nossa populaçâo condiçōes para que conscientemente exercite o seu papel de ajudar, fortalecer a de. mocracia via partidos políticos. Então não há partidos políticos, e sem isso não funciona o sistema parlamentarista de governo. Não funciona. Os partidos têm que ser muito bem organizados, com programas muito bem definidos, com uma disciplina partidária.

E o terceiro ponto importante, que já foi aqui bastante mencionado, é o de uma tecno-burocracia estável, isto é, uma tecno-burocracia permanente, que possa, como muito bem acentuou o Senador Jarbas Passarinho com esse exemplo que ele deu na Itália. Isto é imprescindível para o funcionamento do parlamentarismo, e ele próprio acentuou o porquê nós aqui neste instante não temos condições de adotar o parlamentarismo; porque, como ele muito bem disse, aqui muda o governo e até do mesmo partido, e mudam todos os cargos, desde o secretário do governador ao ascensorista, ao motorista, porque ele já deve ter ouvido muitas inconfidências do outro governo, então não pode servir ao sucessor.

\section{Faltam pré-requisitos ao} parlamentarismo: um Congresso forte com prerrogativas plenas e de boa qualidade. Faltam partidos fortes e muito bem organizados, e falta uma tecno-burocracia estável e também permanente. Isso é imprescindivel. Não existe sistema misto de governo:

Estas coisas a gente também não adquire da noite para o dia. É preciso que haja acesso ao serviço público através de concurso, plano de cargos e salários muito bem definidos, onde 0 acesso e a ascensão se façam através do mérito, e não por aviamento como é uma tradição aqui no nosso país, infelizmente.

Fala-se também no sistema misto, e eu até tenho ouvido nos debates da Constituinte uma confusão muito grande, porque alguns chegam até a imaginar que o sistema parlamentarista, copiando o governo americano, seria a solução, quando lá na verdade é presidencialismo mesmo. Não há parlamentarismo nos EUA. Acontece que lá eles têm conceitos muito bem definidos de democracia e de federação, o que nós não temos aqui. Então é, a meu ver, uma deturpação imaginar-se que nós possamos aqui adotar um sistema misto, e constantemente ouço o exemplo de sistema parlamentarista ou presidencialista misto que poderia ser adotado aqui no Brasil. Não há, absolutamente, condições. E, fora isto, gente, eu acho que ou é presidencialismo, ou parlamentarismo clássico. Não existe sistema misto de governo. Se houvesse esta possibilidade, outros países já a teriam adotado. Não seríamos nós, brasileiros, que de repente iríamos inventar, dentro de um sistema democrático, dentro da democracia que todos nós queremos, um sistema diferente de governo. Ou é parlamentarismo, ou é presidencialismo. Evidentemente, como outros já acentuaram, existem algumas características um pouco diferenciadas no exercício do sistema parlamentarista de governo, dependendo das características do próprio pais.

Nós podemos aqui, isto sim, preparar condiçõoes para, mais tarde, fora de crises, depois que já estivermos bem distantes deste período autoritário de que acabamos de sair, é possivel então, a gente desde logo preparar as condiçōes, adotar alguns pré-requisitos para podermos, lá na frente, tomarmos maduramente a decisão que queremos. Ou sistema parlamentar, ou sistema presidencial de governo. E quais são, no meu entendimento, as providências que precisamos tomar agora na Constituinte para que tenhamos, o mais cedo possível, esse pré-requisito? No meu entendimento, é um voto distrital, porque o sistema parlamentar de governo faliu, ele permite toda uma série de vícios eleitorais na escolha dos parlamentares, e, portanto, eu acho que nós devemos substituir este sistema e devemos ter a coragem de implantar o sistema puro, e não o misto. O misto funciona bem em alguns paises onde o parlamento é unicameral. E num pais como o nosso, onde o Congresso Nacional é bicameral, no meu entendimento não há necessidade de se adotar o sistema distrital misto, como funciona na Alemanha e tantos outros países, e vejo a tendência dos que defendem o sistema distrital aqui no Brasil citarem muito o exemplo alemão. Mas, no meu entendimento, não há necessidade porque, se nós consideramos o sistema proporcional já viciado e superado, para que adotar o 


\section{IDÉIAS}

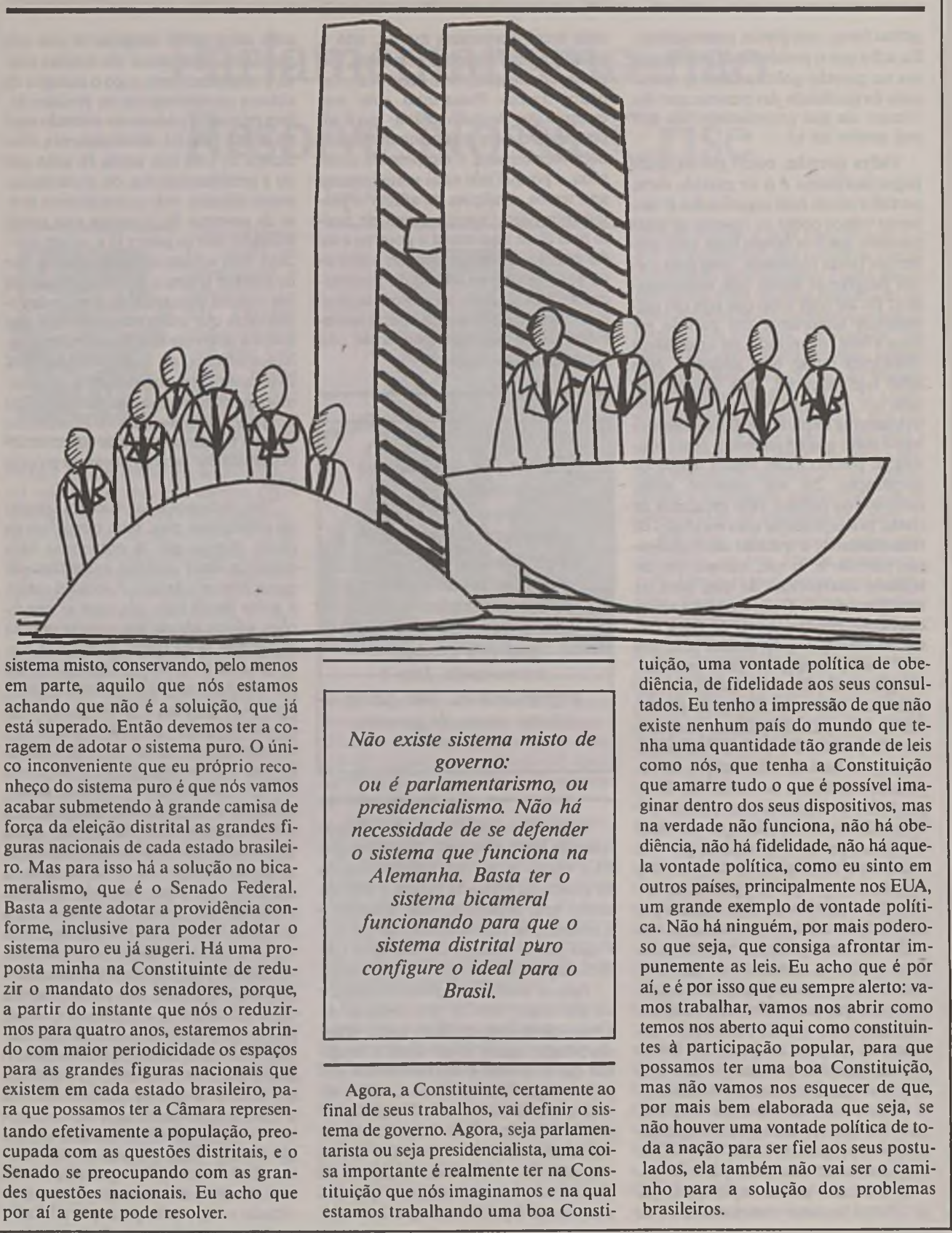

